\title{
Anterior Cruciate Ligament Graft Choices: A Review of Current Concepts
}

\author{
Sujay K. Dheerendra ${ }^{*}, 1$, Wasim S. Khan ${ }^{2}$, Rohit Singhal ${ }^{3}$, Deepak G. Shivarathre ${ }^{4}$, Ravi Pydisetty ${ }^{5}$ \\ and David Johnstone ${ }^{6}$ \\ ${ }^{I}$ Royal Liverpool and Broadgreen University Hospitals NHS Trust, Prescot Street, Liverpool, Merseyside, L7 8XP, UK \\ ${ }^{2}$ University College London Institute of Orthopaedics and Musculoskeletal Sciences, Royal National Orthopaedic \\ Hospital, Stanmore, Middlesex, HA7 4LP, UK \\ ${ }^{3}$ Warrington \& Halton Hospitals NHS Foundation Trust, Lovely lane, Warrington, Cheshire, WA5 1QG, UK \\ ${ }^{4}$ Wirral University Teaching Hospital NHS Foundation Trust, Arrowe Park Road, Upton, Wirral, CH49 5PE, UK \\ ${ }^{5}$ St Helens \& Knowsley Teaching Hospitals NHS Trust, Warrington Road, Prescot, Merseyside, L35 5DR, UK \\ ${ }^{6}$ Stoke Manderville Hospital, Aylesbury, Buckinghamshire, HP21 8AL, UK
}

\begin{abstract}
The graft choice for anterior cruciate ligament (ACL) reconstruction continues to be controversial. There are several options available for the treating surgeon, including Bone Patellar Tendon Bone (BPTB) grafts, Hamstring tendon (HT) grafts, allografts and synthetic grafts. Within the last decade there have been several comparative trials and metaanalysis, which have failed to provide an answer with regards to the best graft available. The aim of this review is to understand the current concepts in graft choices for ACL reconstruction.
\end{abstract}

Keywords: Anterior cruciate ligament, autograft, allograft, bone patellar tendon bone graft, hamstring tendon graft, synthetic graft.

\section{INTRODUCTION}

The surgeon is faced with several dilemmas while treating patients with deficient Anterior Cruciate Ligament (ACL). Once the decision to reconstruct is made the next critical decision is with regards to the graft choice. The factors considered by the surgeon include donor site morbidity, reported rates of graft failure, familiarity with the graft, surgical time, associated complications, ability to restore the patient's activity to pre-injury level and costeffectiveness. The choice of the graft is broadly between an autograft, allograft or a synthetic graft. The two most commonly used autografts are bone-patellar tendon-bone (BPTB) and hamstrings tendon. A recent Cochrane review on the outcomes of BPTB and hamstrings tendon was inconclusive [1]. There have been several studies comparing the outcomes of allografts with autografts [2-8]. The use of synthetic graft is becoming very less considering the associated complications [9-11]. The aim of this review is to understand the current concepts in graft choice for ACL reconstruction.

\section{AUTOGRAFT}

The two most common autografts used currently are BPTB and hamstrings tendon though previously Ilio-tibial band [12] has been used and some surgeons still use quadriceps tendon [13].

*Address correspondence to this author at the 36 Raleigh Close, Warrington, Cheshire, WA5 9QS, UK; Tel: 07834547680;

E-mail: sujaykd@yahoo.com

\section{Bone - Patellar Tendon - Bone (BPTB) Grafts}

In 1969 Kurt Franke pioneered the use of free BPTB grafts consisting one third of patellar tendon and attached patellar and tibial bone block [14]. This is now the gold standard among graft choices against which the effectiveness of the other grafts is compared. The advantages of BPTB graft such as high strength and stiffness, consistency of the size of the graft, ease in harvesting, early graft incorporation and solid fixation using interference screw make it the commonest autograft to be used [15]. However there are several complications associated with the use of BPTB due to harvest site morbidity such as anterior knee pain, pain when kneeling, patellar fracture, late patellar tendon rupture, numbness due to injury to the infra-patellar branch of the saphenous nerve and loss of quadriceps function [16].

\section{Hamstring Tendon Grafts}

To avoid the harvest site morbidity associated with the BPTB grafts Lipscomb in 1982 started using the pes anserinus (semitendinosus and gracilis) tendons pedicled on the tibia [17]. It was in 1988 that Friedman pioneered the use of an arthroscopically assisted four stranded hamstring graft technique [18]. There has now been an increased popularity of the hamstring tendons in the recent years. The tendons once harvested are looped over to create a quadruple strand structure, which is then sutured together to make the final graft. There is a perception that hamstring grafts are associated with less donor site morbidity but studies have still reported presence of anterior knee pain and kneeling discomfort though in lesser incidence compared to BPTB 
grafts [19-22]. There have been several studies [23, 24] suggesting that the hamstring tendons have a capacity to regenerate into a 'tendon like' structure, which allows full recovery of the hamstring function and has also been used in revision ACL reconstruction [25].

Early rehabilitation being key to the success of ACL reconstruction graft fixation in hamstring tendon proved a challenge initially. However with the advent of soft tissue interference screws and endo-buttons the fixation strength is comparable to the BPTB grafts.

\section{BPTB vs Hamstring Tendon Graft}

The early criticism towards HT graft was of poor strength and stiffness however with improved techniques, the quadruple stranded grafts were comparable to native ACL. There have been several studies published in the literature studying the biomechanical aspects of ACL reconstruction with either BPTB or HT grafts. However most of the studies used inappropriately sized grafts or different fixation techniques. Wilson et al. [26] using the same fixation techniques found that the quadruple stranded HT graft has an average load failure of 2,422 $\mathrm{N}$ versus $1,784 \mathrm{~N}$ for the BPTB graft. There was no statistically significant difference in stiffness between the two grafts.

Since 2000 there have been several controlled trials comparing the clinical outcomes of BPTB and HT grafts for ACL reconstruction. It is worth noting that most of these studies used various fixation methods, patient outcome measures and different periods of follow up, which necessitates one to assess the quality of each study. Ejerhed et al. reported a prospectively randomised study comparing the BPTB with the HT graft for ACL reconstruction [20]. A single surgeon performed the procedure where both the types of graft were fixed using interference screws. 71 patients were included in the study and the manual Lachmann's test and KT 1000 arthrometer (MEDmetric Corp., San Diego, California) were used to assess stability. The Lysholm score, Tegner activity level and International Knee Documentation Committee (IKDC) scores were also used to assess the outcome. At 2 year follow-up there was no statistically significant difference among any outcome measure apart from patients in the HT group were able to walk on the knee significantly better than BPTB group.

Laxdal et al. in a similarly designed prospective randomised study compared BPTB grafts with 3 strand semitendinosus (ST) graft and 4 strand ST and gracilis graft [22]. There were 125 patients with an average of 2 years follow up. There was no significant difference in clinical outcome measures but once again patients in the ST and ST$\mathrm{G}$ groups were significantly more able to walk on the knee compared to the BPTB group.

Holm et al. in a prospectively randomised study compared the clinical outcomes and prevalence of osteoarthritis in the BPTB and HT groups [27]. 79\% of the patients who were eligible for follow up at 10 years showed no statistically significant difference in the clinical outcomes. There was a significantly higher prevalence of osteoarthritis in the injured knee however there was no significant difference between the two groups.
Ibrahim et al. reported on 110 consecutive cases with a mean follow up of 81 months [28]. Endo-Button was used to fix the graft in the HT group and interference screws were used in the BPTB group. $78.5 \%$ in the BPTB group and $91 \%$ in the HT group reported overall good results. There was no statistically significant difference between the return to activity between the two groups. However interestingly they found that there was an increase in incidence of early degenerative changes, fixed flexion and extension deformity and patellofemoral pain in the BPTB group. They suggested that HT graft was more suitable for their cohort of predominantly Muslim who were required to kneel to pray on a daily basis.

Harilainen et al. conducted a prospective randomised controlled trial in 99 patients comparing outcomes for BPTB graft fixed with interference screw and HT graft fixed proximally with a suspension fixation similar to EndoButton but made by cutting an AO plate and using Dacron loop to connect the graft to the plate, distally the graft was secured by tying it around a $4.5 \mathrm{~mm}$ cortical screw with a spiked washer over the graft ends [29]. There was no statistically significant difference in the Lysholm score, IKDC score, Kujala patellofemoral score and Tegner activity levels between two groups and also between 2 and 5 year follow up. There was also no statistically significant difference between women and men. There was no statistically significant difference in the radiological measurement of the joint space between the two groups at 2 and 5 year follow up.

There have been some studies that do not show comparable results between the two groups. Aune et al. in a prospective randomised controlled trial of 72 patients showed better kneeling and single leg hopping at 6 and 12 months in the HT tendon group [30]. The HT tendon group also had better isokinetic extension strength at 6 month but no difference in 12 and 24 month follow up. There was a significant weakness in the isokinetic flexion strength in the HT tendon group compared to BPTB group. Beynnon et al. showed weaker knee flexion in the HT group using 2 strand semitendinosus tendon compared to BPTB graft at 3 years [31]. These findings are contradictory to the hypothesis of hamstring tendon regeneration.

Since the year 2000 there have been fourteen published reviews comparing BPTB and HT autografts [1, 32-44]. These reviews varied in their methodology leading to biased conclusion. Three reviews among these restricted their literature search to Medline and English literature, which could lead to publication bias by the authors [36, 37, 44]. These studies also included non-randomised clinical trials. Poolman et al. conducted a review of systematic reviews in 2007 and included 11 systematic reviews [45]. The purpose of this study was to address the discrepancies and contradictory recommendations. Amongst their conclusions were that the existing reviews were of variable quality, sensitivity analyses were inconsistently applied, and that only two reviews $[33,34]$ were found to be methodologically sound. They concluded that the best evidence from methodologically sound meta-analysis suggests that HT grafts are superior in preventing anterior knee pain and there is limited evidence that BPTB grafts provide more stability than HT grafts. 
After a review of several recent studies it is clear that the controversy regarding the superior autograft is far from over. Several well designed prospective randomised trials, though of lower sample size, do not show a significant difference between the two grafts apart from lesser incidence of anterior knee pain in the HT group. There is still no sound evidence to disprove that BPTB grafts are gold standard for ACL reconstruction.

\section{ALLOGRAFTS}

The demand for the use of allograft has been steadily increasing over the last decade and is expected to rise. This is because allografts are able to completely eliminate disadvantages associated with donor site morbidity. Eugene Bircher better known for his pioneering work on arthroscopy conveyed his experience with kangaroo tendon as an augment as well as a sole graft in 1929 and was followed by Micheli who published his results 4 years later [46, 47]. Kangaroo grafts however remained to be used rarely like other xenografts, however the use of human tissues such as tibialis anterior tendon, calcaneal tendons, patellar and Achilles tendons gained popularity [48]. However in the nineties the allograft became unpopular due to increased risk of viral disease transmission (e.g. HIV, Hepatitis C). Sterilisation methods prevalent during those days were known to affect the collagen structure and the mechanical properties of the graft [49]. However, with the advent of graft friendly sterilisation techniques Allografts have gained back some ground [50]. With proper aseptic tissue procurement, sterilisation and donor screening the disease transmission through allografts are on decline. The rate of HIV transmission from a properly screened allograft is about 1 in 1.5 million. In addition to screening the allografts can also be sterilised [51]. The techniques that are not currently used (high dose radiation and ethylene glycol sterilisation) could have resulted in a structurally weak graft tissue leading to poor functional outcomes. Some tissue banks now just rely on aseptic procurement of the grafts or sterilise with other proprietary chemical solutions. Hence it is important to know about the graft procurement and sterilisation technique when analysing a research study.

Other disadvantages with using an allograft include the immunogenic response of the host to the graft and delayed graft incorporation when compare to the autografts. In a histological study assessing 9 allografts retrieved during autopsy at 2 years showed poor vascularisation in the centre portion of the graft, which had remained acellular [52]. Thus unlike previous reports of good incorporation of allograft at 18 months [53] this study shows that the incorporation might take 3 years or more. However despite the above concerns allografts are still frequently used and it is important to analyse if the data supports the use of allogrfafts in ACL reconstruction.

Ho Noh et al. in a recently published randomised controlled trial comparing free Achilles tendon allograft to HT grafts in 65 patients followed up for 2 years. There found that short term outcomes including Lachmann test, IKDC score, Lysholm score and Tegner daily activities score, were comparable to the autogenous HT graft [54].

Foster et al. conducted a recent systematic review of level I and II studies to analyse the graft sources affecting the functional outcomes in ACL reconstruction [55]. Out of the 31 studies that were included, 27 studies with 2,184 patients examined autograft reconstructions and only 4 studies with 137 patients examining allograft reconstructions. They found that prospective data comparing allograft versus autograft were scarce and the studies had small populations. Despite this there was no difference in the outcomes for allografts compared to autografts in patients with upto 6 year follow up.

Victor et al. looked at the long term morbidity associated with BPTB allografts when compared to autogenous BPTB grafts [56]. They found no significant difference in the morbidity at 2 years however they found that 3 tendon ruptures out of the 25 patients in the allograft group. Because of this they hypothesised that some allografts might not revascularise and act as passive restraints until they fail from fatigue and abrasion. Kleipool et al. looked at 36 BPTB allograft patients versus 26 autograft patients with a mean of 46 months follow up [57]. They reported a trend of improved functional outcomes in the allograft group however they were not statistically significant. They also did not find any difference in graft integrity and overall morbidity. Edgar et al. evaluated the outcomes for hamstring allograft and autograft reconstruction and found similar laxity and functional scores in both the groups at 3 and 6 ears follow up [58].

There are not many studies comparing the outcomes between two allografts, which would help determine which the best available allograft was. Siebold et al. in a study comparing BPTB allograft $(n=183)$ and Achilles tendon allografts $(n=42)$ with an average follow up of 37.7 months showed comparable results with lower failure rate in Achilles tendon bone allograft.

Interestingly in terms of this review the reduction in morbidity when using an allograft has not been supported. There is also a risk, although rare, of disease transmission in allografts. Despite these risks some investigators still believe in the role of allografts in ACL reconstruction.

\section{SYNTHETICS}

To overcome the disadvantages associated with allografts while keeping the benefits such as lack of donor site morbidity and easier surgical technique, there was an enthusiasm towards synthetic grafts in the early nineties. In 1981, Dandy et al. first implanted a carbon fibre reinforced substitute for ACL through an arthroscopic method. However, after encouraging preliminary results there were reports of early ruptures due to poor resistance to torsion forces leading to carbon deposition in the liver and inflammatory synovitis in the knee [59].

In 1986 ligaments made by expanded polytetraflouroethylene (PTFE) (Gore-Tex) grafts were approved in the US for use in failed autologous grafts. These synthetic ligaments had a very high ultimate tensile strength and also stiffness. They had vey encouraging results initially [60] but later studies showed complications in $76 \%$ of the cases [61] with upto $29 \%$ graft failure rate [62], tunnel osteolysis [63] and deposits of PTFE particles in lymph nodes distant to the knee [64]. They were eventually withdrawn from the market in 1993. 
The Dacron ligament came to be used for ACL reconstruction after having been used in the acromioclavicular joint injuries. This ligament is made of polyester and is designed to replace the ACL permanently. Despite initial encouraging results [65] a very high rupture rate ranging from $29 \%$ to $60 \%$ were reported in the literature $[66,67]$. While presenting the long term outcomes authors also noted that $83 \%$ of the patients had degenerative changes in the knee joint with only $14 \%$ of patients having an acceptable stability and functional outcome [66]. This product was later withdrawn from the market in 1994.

The Leeds - Keio (LK) ligament was developed in 1982 from collaboration between University of Leeds, UK and University of Keio, Japan. It is made by woven polyester fibers constituting a tubular bundle measuring $10 \mathrm{~mm}$ in diameter. The LK ligament is a "scaffold" type of prosthesis, as it acts as an inducer for tissue ingrowth; porous coating allows the induction of biological tissue and promotes the formation of a neo-ligament on the intra-articular portion. In a study of 152 patients with a follow-up of more than four years: $90.1 \%$ had a negative Lachman test and $82.2 \%$ a negative anterior drawer sign; no major complications were noticed. Second-look arthroscopies performed three and six months after surgery reported a good coverage of the implanted ligament; ruptures occurred only in $3.3 \%$ of cases [68]. Engstrom et al. in a prospective randomised controlled trial comparing LK ligament versus autologous BPTB grafts noticed increased anterior laxity and positive pivot shift test after an average follow up of 27 months [69].

After all the previous discouraging results from artificial ligaments used for ACL reconstruction there has been some encouraging reports regarding the use of Ligament Advanced Reinforcement System (LARS ligament). These ligaments are made of polyethylene terephtalate and their structure allows tissue ingrowth in the intra-articular part. Lavoie et al. presented their study of 47 patients with a follow up of 8 to 45 months with good results in subjective parameters and satisfying Tegner activity level. A subsequent study from the same group comparing the results to BPTB autografts showed comparable results with better subjective and objective findings for LARS ligament in the early years. The results with LARS ligament are promising however long term results are awaited.

Research in the field of artificial ligaments demonstrates that the ultimate characteristic required for these materials is biocompatibility. The mechanical properties should also be similar to the natural ligament. Despite several studies, every material has been found to have a drawback and the search for the ideal synthetic graft is ongoing.

\section{CONCLUSION}

Through this review it is clear that a perfect graft for ACL reconstruction continues to be a myth. The decision making for the surgeon with regards to the graft choice is dependent on the familiarity with the surgical technique. Several patient factors such as the nature of the job and religion should also be taken into consideration while arriving at a decision. There is still a lack of evidence to refute the claim that BPTB autologous grafts as the gold standard. The association of higher donor site morbidity i.e. anterior knee pain has also not been proven beyond doubt in several prospective randomised studies comparing the BPTB grafts with HT autografts, several allografts and even synthetic grafts. The lack of statistically significant results could be attributed to the low number of patients in the study groups. It was also noted during this review that there are no standard outcome measures being employed to evaluate the outcomes, which could lead to difficulty in generalising the results from a single unit. This review has not taken into consideration other factors playing a role in graft failure such as graft fixation method and also early rehabilitation process, which are also currently controversial.

Further research is necessary to standardise the processes involved in ACL reconstruction including the graft choice, graft fixation methods and rehabilitation protocols. There should also be a national registry such as the national joint registry, which could enable future monitoring of ACL reconstruction techniques and outcomes.

\section{ACKNOWLEDGEMENT}

None declared.

\section{CONFLICT OF INTEREST}

The author(s) confirm that this article content has no conflicts of interest.

\section{REFERENCES}

[1] Mohtadi NG, Chan DS, Dainty KN, Whelan DB. Patellar tendon versus hamstring tendon autograft for anterior cruciate ligament rupture in adults. Cochrane Database Syst Rev 2011; 9: CD005960. Review.

[2] Mehta VM, Mandala C, Foster D, Petsche TS. Comparison of revision rates in bone-patella tendon-bone autograft and allograft anterior cruciate ligament reconstruction. Orthopedics 2010; 33(1): 12.

[3] Shelton WR, Papendick L, Dukes AD. Autograft versus allo- graft anterior cruciate ligament reconstruction. Arthroscopy 1997; 13: 446-9.

[4] Harner CD, Olson E, Irrgang JJ, Silverstein S, Fu FH, Silbey M. Allograft versus autograft anterior cruciate ligament reconstruction; 3- to 5-year outcome. Clin Orthop 1996; 324: 134-44.

[5] Victor J, Bellemans J, Witvrouw E, Govaers K, Fabry G. Graft selection in anterior cruciate ligament reconstruction-Prospective analysis of patellar tendon autografts compared with allografts. Int Orthop 1997; 21: 93-7.

[6] Kleipool AEB, Zijl JAC, Willems WJ. Arthroscopic anterior cruciate ligament reconstruction with bone-patellar tendon- bone allograft or autograft: A prospective study with an aver- age follow-up of 4 years. Knee Surg Sports Traumatol Arthrosc 1998; 6: 224-30.

[7] Peterson RK, Shelton WR, Bomboy AL. Allograft versus autograft patellar tendon anterior cruciate ligament reconstruc- tion: A 5-year follow-up. Arthroscopy 2001; 17: 9-13.

[8] Stringham DR, Pelmas CJ, Burks RT, Newman AP, Marcus RL. Comparison of anterior cruciate ligament reconstructions using patellar tendon autograft or allograft. Arthroscopy 1996; 12: 41421.

[9] Larson RL. Gore-tex anterior cruciate ligament reconstruction. In: Scott WN, Ed. Ligament and extensor mechanism injuries of the knee: diagnosis and treatment. St. Louis: Mosby Year Book 1991; pp. 319-29.

[10] Woods GA, IndelicatoPA, PrevotTJ. The Gore-tex anterior cruciate ligament prosthesis. Two versus three year results. Am J Sports Med 1991; 19: 48-55.

[11] Maletius W, Gillquist J. Long-term results of anterior cruciate ligament reconstruction with a Dacron prosthesis. The frequency of osteoarthritis after seven to eleven years. Am J Sports Med 1997; 25(3): 288-93.

[12] Frank CB, Jackson DW. The science of reconstruction of the anterior cruciate ligament. J Bone Joint Surg Am 1997; 79: 155676. 
[13] Noronha JC. Reconstruction of the anterior cruciate ligament with quadriceps tendon. Arthroscopy 2002; 18: E37.

[14] Franke K. Clinical experience in 130 cruciate ligament reconstructions. Orthop Clin North Am 1970; 7: 101-2.

[15] Fineberg MS, Zarins B, Sherman OH. Practical considerations in anterior cruciate ligament replacement surgery. Arthroscopy 2000; 16: 715-24.

[16] Busam ML, Provencher MT, Bach BR Jr. Complications of anterior cruciate ligament reconstruction with bone-patellar tendonbone constructs: care and prevention. Am J Sports Med 2008; 36(2): 379-94.

[17] Lipscomb AB, Jonhston RK, Synder RB, et al. Evaluation of hamstring strength following use of semitendinosus and gracilis tendons to reconstruct the anterior cruciate ligament. Am J Sports Med 1982; 10: 340-42.

[18] Friedman MJ. Arthroscopic semitendinosus (gracilis) reconstruction for anterior cruciate ligament deficiency. Tech Orthop 1988; 2: 74-80.

[19] Aglietti P, Giron F, Buzzi R, Biddau F, Sasso F. Anterior cruciate ligament reconstruction: bone-patellar tendon-bone compared with double semitendinosus and gracilis tendon grafts. A prospective, randomized clinical trial. J Bone Joint Surg 2004; 86(10): 2143-55.

[20] Ejerhed L, Kartus J, Sernert N, Kohler K, Karlsson J. Patellar tendon or semitendinosus tendon autografts for anterior cruciate ligament reconstruction? A prospective randomized study with a two-year follow-up. Am J Sports Med 2003; 31(1): 19-25.

[21] Feller JA, Webster KE. A randomized comparison of patellar tendon and hamstring tendon anterior cruciate ligament reconstruction. Am J Sports Med 2003; 31(4): 564-73.

[22] Laxdal G, Kartus J, Hansson L, Heidvall M, Ejerhed L, Karlsson J. A prospective randomized comparison of bone-patellar tendonbone and hamstring grafts for anterior cruciate ligament reconstruction. Arthroscopy 2005; 21(1): 34-42.

[23] Cross MJ, Roger G, Kujawa P, Anderson IF. Regeneration of the semitendinosus and gracilis tendons following their transaction for repair of the anterior cruciate ligament. Am J Sports Med 1992; 20: 221-3.

[24] Ferretti A, Conteduca F, Morelli F, Masi V. Regeneration of the semitendinosus tendon after its use in anterior cruciate ligament reconstruction: a histologic study of three cases. Am J Sports Med 2002; 30: 204-7.

[25] Yoshiya S, Matsui N, Matsumoto A, Kuroda R, Lee S, Kurosaka M. Revision anterior cruciate ligament reconstruction using the regenerated semitendinosus tendon: analysis of ultrastructure of the regenerated tendon. Arthroscopy 2004; 20(5): 532-5.

[26] Wilson TW, Zafuta MP, Zobitz M. A biomechanical analysis of matched bone-patellar tendon-bone and double-looped semitendinosus and gracilis tendon grafts. Am J Sports Med 1999; 27: 202-7.

[27] Holm I, Oiestad BE, Risberg MA, Aune AK. No difference in knee function or prevalence of osteoarthritis after reconstruction of the anterior cruciate ligament with 4-strand hamstring autograft versus patellar tendon-bone autograft: a randomized study with 10-year follow-up. Am J Sports Med 2010; 38(3): 448-54.

[28] Ibrahim SA, Al-Kussary IM, Al-Misfer AR, Al-Mutairi HQ, Ghafar SA, El Noor TA. Clinical evaluation of arthroscopically assisted anterior cruciate ligament reconstruction: patellar tendon versus gracilis and semitendinosus autograft. Arthroscopy 2005; 21(4): 412-7.

[29] Harilainen A, Linko E, Sandelin J. Randomized prospective study of ACL reconstruction with interference screw fixation in patellar tendon autografts versus femoral metal plate suspension and tibial post fixation in hamstring tendon autografts: 5-year clinical and radiological follow-up results. Knee Surg Sports Traumatol Arthrosc 2006; 14: 517-28.

[30] Aune AK, Holm I, Risberg MA, Jensen HK, Steen H. Four-strand hamstring tendon autograft compared with patellar tendon-bone autograft for anterior cruciate ligament reconstruction. A randomized study with two-year follow-up. Am J Sports Med 2001; 29(6): 722-8.

[31] Beynnon BD, Johnson RJ, Fleming BC, et al. Anterior cruciate ligament replacement. Comparison of bone-patellar tendon-bone grafts with two-strand hamstring grafts; a prospective randomized study. J Bone Joint Surg Am 2002; 84: 1503-13.
[32] Biau DJ, Tournoux C, Katsahian S, Schranz P, Nizard R. ACL reconstruction: A meta-analysis of functional scores. Clin Orthop Relat Res 2007; 458: 180-7.

[33] Biau DJ, Tournoux C, Katsahian S, Shranz PJ, Nizard RS. Bonepatellar tendon-bone autografts versus hamstring autografts for reconstruction of anterior cruciate ligament: meta-analysis. BMJ 2006; 332(7548): 995-1001.

[34] Dauty M, Tortellier L, Rochcongar P. Isokinetic and anterior cruciate ligament reconstruction with hamstrings or patella tendon graft: analysis of literature. Int J Sports Med 2005; 26(7): 599-606.

[35] Forster MC, Forster IW. Patellar tendon or four-strand hamstring? A systematic review of autografts for anterior cruciate ligament reconstruction. Knee 2005; 12 (3): 225-30.

[36] Freedman KB, D'Amato MJ, Nedeff DD, Kaz A, Bach BR. Arthroscopic anterior cruciate ligament reconstruction: a metaanalysis comparing patellar tendon and hamstring tendon autografts. Am J Sports Med 2003; 31: 2-11.

[37] Goldblatt JP, Fitzsimmons SE, Balk E, Richmond JC. Reconstruciton of the anterior cruciate ligament: meta-analysis of patellar tendon versus hamstring tendon autograft. Arthroscopy 2005; $21: 791-803$.

[38] Grant JA, Mohtadi NG. ACL reconstruction with autografts. Weighing performance considerations and postoperative care. Phys Sportsmed 2003; 31(4): 27-40.

[39] Herrington L, Wrapson C, Matthews M, Matthews H. Anterior cruciate ligament reconstruction, hamstring versus bone-patella tendon-bone grafts: a systematic literature review of outcome from surgery. Knee 2005; 12(1): 41-50.

[40] Prodromos CC, Joyce BT, Shi K, Keller BL. A meta-analysis of stability after anterior cruciate ligament reconstruction as a function of hamstring versus patellar tendon graft and fixation type. Arthroscopy 2005; 21(10): 1202.

[41] Schultz WR, Carr CF. Comparison of clinical outcomes of reconstruction of the anterior cruciate ligament: autogenous patellar tendon and hamstring grafts. Am J Orthop 2002; 31(11): 613-20.

[42] Spindler KP, Kuhn JE, Freedman KB, Matthews CE, Dittus RS, Harrell FE. Anterior cruciate ligament reconstruction autograft choice: bone-tendon-bone versus hamstring: does it really matter? A systematic review. Am J Sports Med 2004; 32: 1986-95.

[43] Thompson J, Harris M, Grana WA. Patellofemoral pain and functional outcome after anterior cruciate ligament reconstruction: an analysis of the literature. Am J Orthop 2005; 34(8): 396-9.

[44] Yunes M, Richmond JC, Engels EA, Pinczewski LA. Patellar versus hamstring tendons in anterior cruciate ligament reconstruction: A meta-analysis. Arthroscopy 2001; 17: 248-57.

[45] Poolman RW, Abouali JAK, Conter HJ, Bhandari M. Overlapping systematic reviews of anterior cruciate ligament reconstruction comparing hamstring autograft with bone-patellar tendon-bone autograft: Why are they different?. J Bone Joint Surg Am 2007; 89: 1542-52.

[46] Bircher E. Über Kreuzbandverletzungen [On cruciate ligament injuries]. Zentralbl Chir 1930; 57: 2207.

[47] Micheli E. Riconstruzione dei legamenti crociati delginocchio con tendine di canguro. Risolto a distanza. Boll Mem Soc Piemont Chir 1933; 3: 874-83

[48] Shino K, Kimura T, Hirose H, Inoue M, Ono K. Reconstruction of the anterior cruciate ligament by allogeneic tendon graft. An operation for chronic ligamentous insufficiency. J Bone Joint Surg 1986; 68-B: 739-46.

[49] Smith CW, Young IS, Kearney JN. Mechanical properties of tendons: changes with sterilisation and preservation. J Biomech Eng 1996; 118: 56-61.

[50] Rasmussen TJ, Feder SM, Butler DL, Noyes FR. The effect of 4 mrad gamma irradiation on the initial mechanical properties of bone-patellar tendon-bone grafts. Arthroscopy 1994; 10: 188-97.

[51] Barber AF, McGuire DA, Johnson DH. Point counterpoint: Should allografts be used for routine anterior cruciate ligament reconstructions? Arthroscopy 2003; 19: 421-5.

[52] Malinin TI, Levitt RL, Bashore C, Temple HT, Mnaymneh W. A study of retrieved allografts used to replace anterior cruciate ligaments. Arthroscopy 2002; 18: 163-70.

[53] Shino K, Inoue M, Horibe S, Nagano J, Ono K. Maturation of allograft tendons transplanted in the knee. J Bone Joint Surg Br 1988; 70: 556-60.

[54] Noh JH, Yi SR, Song SJ, Kim SW, Kim W. Comparison between hamstring autograft and free tendon Achilles allograft: minimum 2- 
year follow-up after anterior cruciate ligament reconstruction using EndoButton and Intrafix. Knee Surg Sports Traumatol Arthrosc 2011; 19(5): 816-22.

[55] Foster TE, Wolfe BL, Ryan S, Silvestri L, Kaye EK. Does the graft source really matter in the outcome of patients under- going anterior cruciate ligament reconstruction? An evaluation of autograft versus allograft reconstruction results: a systematic review. Am J Sports Med 2010; 38: 189-99.

[56] Victor J, Bellemans J, Witvrouw E, Govaers K, Fabry G. Graft selection in anterior cruciate ligament reconstruction-Prospective analysis of patellar tendon autografts compared with allografts. Int Orthop 1997; 21: 93-7.

[57] Kleipool AE, Zijl JA, Willems WJ. Arthroscopic anterior cruciate ligament reconstruction with bone-patellar tendon-bone allograft or autograft: a prospective study with an average follow up of 4 years. Knee Surg Sports Traumatol Arthrosc 1998; 6(4): 224-30.

[58] Edgar CM, Zimmer S, Kakar S, Jones H, Schepsis AA. Prospective comparison of auto and allograft hamstring tendon constructs for ACL reconstruction. Clin Orthop Relat Res 2008; 466(9): 2238-46.

[59] Rushton N, Dandy DJ, Naylor CPE. The clinical, arthroscopic and histological findings after replacement of the anterior cruciate ligament with carbon-fiber. J Bone Joint Surg Br 1983; 65: 308-9.

[60] Ahlfeld SK, Larson RL, Collins RH. Anterior cruciate reconstruction in the chronically unstable knee using an expanded polytetrafluoroethylene (PTFE) prosthetic ligament. Am J Sports Med 1987; 15: 326-30.

[61] Paulos LE, Rosenberg TD, Grewe SR, Tearse DS, Beck CL. The GORE-TEX anterior cruciate ligament prosthesis: a long-term follow-up. Am J Sports Med 1992; 20: 245-52.
[62] Sledge SL, Steadman JR, Silliman JF, Peloza J, Flistone HA. Fiveyear results with the Gore-Tex anterior cruciate ligament prosthesis. Am J Knee Surg 1992; 5: 65-70.

[63] Seemann MD, Steadman JR. Tibial osteolysis associated with Gore-Tex grafts. Am J Knee Surg 1993; 6: 31-8.

[64] Wilson WJ, Lesis F, Scranton PE. Combined reconstruction of the anterior cruciate ligament in competitive athletes. J Bone Joint Surg Am 1990; 72A: 742-8.

[65] Lukianov AV, Richmond JC, Barrett GR, Gillquist J. A multicenter study on the results of anterior cruciate ligament reconstruction using a Dacron ligament prosthesis in "salvage" cases. Am J Sports Med 1998; 17: 380-6.

[66] Gillquist J, Odensten M. Reconstruction of old anterior cruciate ligament tears with a Dacron prosthesis. A prospective study. Am J Sports Med 1993; 21: 358-66.

[67] Barrett GR, Line LL, Shelton WR, Manning JO, Phelps R. The Dacron ligament prosthesis in anterior cruciate ligament reconstruction. A four-year review. Am J Sports Med 1993; 21: 367-73.

[68] Fujikawa K. Clinical study of anterior cruciate ligament reconstruction with the Leeds-Keio artificial ligament. In: Friedman MJ, Ed. Prosthetic ligament reconstruction of the knee. Philadelphia, PA: WB Saunders 1988.

[69] Engström B, Wredmark T, Westblad P. Patellar tendon or LeedsKeio graft in the surgical treatment of anterior cruciate ligament ruptures. Intermediate results. Clin Orthop Rel Res 1993; 295: 1907.

(C) Dheerendra et al.; Licensee Bentham Open.

This is an open access article licensed under the terms of the Creative Commons Attribution Non-Commercial License (http://creativecommons.org/licenses/by-nc/3.0/) which permits unrestricted, non-commercial use, distribution and reproduction in any medium, provided the work is properly cited. 